БЕЛУГИНА Надежда Борисовна - ассистент департамента массовых коммуникаций и медиабизнеса Финансового университета при Правительстве РФ (125993, Россия, г. Москва, ГСП-3, Ленинградский np-кm, 49; belugina.nb@gmail.com)

РЯЗАНОВА Лилия Вячеславовна - менеджер Института финансовой грамотности Финансового университета при Правительстве РФ (125993, Россия, г. Москва, ГСП-3, Ленинградский пр-кт, 49; liliya_ryazanova@mail.ru)

\title{
ИНФОРМАЦИОННЫЕ ПОТОКИ РАДИКАЛОВ В РУНЕТЕ НАКАНУНЕ И ПОСЛЕ ЕДГ-2021: КОНТЕКСТЫ, ТАРГЕТНЫЕ ГРУППЫ И МАСШТАБ ОБЩЕСТВЕННОЙ ПОДДЕРЖКИ
}

\begin{abstract}
Аннотация. В статье представлены результаты сравнительного анализа количественных, структурных и содержательных параметров сообщений пользователей социальных медиа, связанных с радикальными информационными потоками накануне и после ЕДГ-2021. Модель исследования представляет комбинирование методов киберметрического и дискурс-анализа онлайн-контента, генерируемого пользователями российского сегмента социальных медиа и связанного с темой выборов в 2021 г. Исследование позволило выявить количественные и качественные изменения в радикальной информационной повестке, тематическое распределение дискурса информационных потоков.
\end{abstract}

Ключевые слова: интернет-пространство, социальные медиа, политическая коммуникация, политический дискурс, киберметрический анализ, дискурс-анализ, протестная активность

Исследование выполнено при финансовой поддержке РФФИ и ЭИСИ в рамках научного проекта № 21-011-31161 «цировые сетевые структуры радикальной оппозиции в Россиш».

Введение. Под воздействием современных процессов информатизации массовых коммуникаций меняется и пространство политических коммуникаций. Социальные медиа выступают сегодня в качестве эффективного инструмента мобилизации и активизации деструктивных коммуникативных практик на фоне разнообразия альтернативных оппозиционных каналов коммуникации. Внедрение дистанционных технологий голосования, начавшееся в 2020 г. в ряде субъектов РФ, способствовало развитию цифровых форм политического участия в РФ и повышению интенсивности интернет-коммуникации различных политических сил с таргетными группами. Более того, выход московской негативной повестки относительно дистанционного электронного голосования за пределы столичного инфополя привело к тому, что оппозиционная повестка в рамках ЕДГ поддерживалась при помощи инфоповодов, связанных с критикой действующей власти.

Активизация радикального дискурса выдвинула задачу анализа информационных потоков в Рунете в период до и после ЕДГ в 2021 г.

Теоретико-методологическая основа исследования. Методология исследования имеет междисциплинарный характер и базируется на следующих теориях и подходах:

- сетевой подход [Knoke 1990; Сморгунов 2019], отражающий идею сложноорганизованной системы взаимоотношений акторов во взаимодействии в сети;

- теория информационных волн [Чернявская 2014], в основе которой лежит масштабное общественно значимое событие, тиражируемое СМИ. Пик 
информационной волны возникает при подключении целевой аудитории к распространению и обсуждению информационного повода;

- теория политического дискурса [Чурашова 2013], которая предполагает деление политического дискурса, применяемого акторами в кризисных ситуациях, на дискурс обвинения и дискурс защиты.

Радикальный контент в социальных медиа идентифицируется как содержащий следующие признаки:

- признание необходимости кардинальных, скачкообразных, коренных изменений в социальной жизни и/или политическом устройстве общества;

- непримиримость в отношении к действующей власти, бескомпромиссность (резкая оппозиционность);

- стремление к моментальным, скоротечным изменениям в социальном и/ или политическом устройстве общества;

- искусственность конструируемых образов желаемого будущего [Домбровская 2021б].

Использование перечисленных подходов и теорий в настоящем исследовании направлено на выявление особенностей динамики и структуры информационных потоков, связанных с нарастанием радикализации политических коммуникаций в период ЕДГ-2021 (8-27 сентября 2021 г.).

Методика исследования базируется на принципах социально-медийной предиктивной аналитики, позволяющей провести детальный анализ практик партийных сообществ в онлайн-среде на основе поиска открытых цифровых следов в крупнейших социальных медиа посредством применения автоматизированных инструментов сбора и обработки данных [Бродовская и др. 2018; Домбровская 2021а; Пырма 2020]. Выборочную совокупность составляют сообщения, аккумулированные с помощью онлайн-сервиса мониторинга социальных медиа IQBuzz. Хронологические рамки исследования определяются временем проведения ЕДГ-2021.

Результаты исследования. На основе полученных данных при проведении когнитивного картирования нами были выделены следующие группы дискурсов: дискурс несвободы слова и СМИ в РФ, дискурс ущемления прав личности в России, дискурс мобилизации протестных настроений, дискурс осудительного отношения к ограничительным мерам по нераспространению пандемии, дискурс осудительного отношения к сторонникам президента и дискурс осудительного отношения к президенту и действующей власти в целом.

Дискурс несвободы слова и СМИ в РФ.

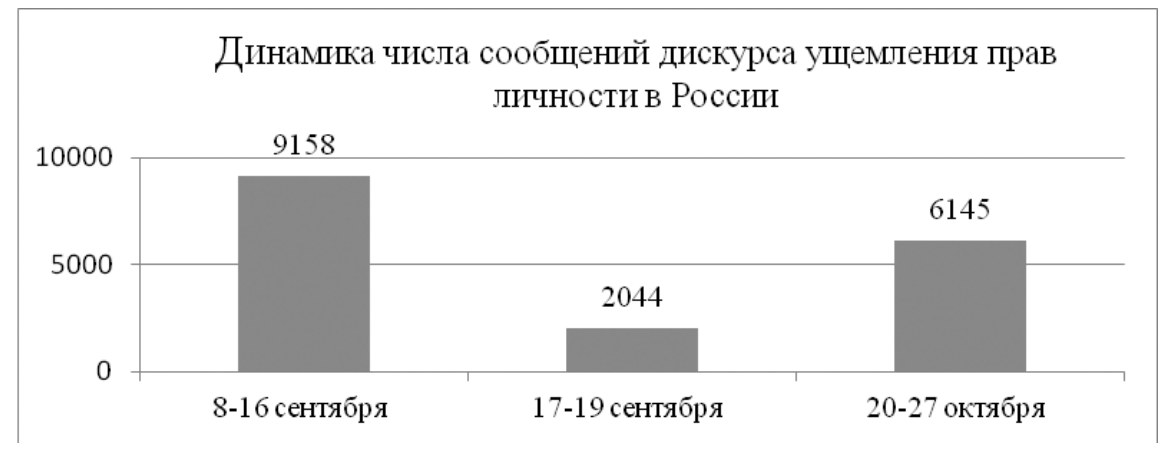

Рисунок. 1. Дискурс несвободы слова и СМИ в РФ 
Дискурс несвободы слова и СМИ в РФ маркирован высокой активностью с 8 по 16 сентября, в последующие периоды наблюдается его вытеснение дискурсами мобилизации гражданской протестной активности (см. рис. 1). Социально-демографические показатели активных периодов имеют маскулинный перевес - 71,1\% против 70,6\%.

Социальная база информационных потоков наиболее активных периодов анализа характеризуется схожей тенденцией: чаще всего свое мнение высказывали представители 26-35 лет и 36-45 лет. Таким образом, можно констатировать, что дискурс несвободы слова и СМИ в РФ в большей степени артикулирован среди экономически активного мужского населения.

Анализ частотности употребления слов информационного потока показал, что в десятку наиболее употребляемых слов всех временных отрезков входят такие дефиниции, как «человек», «пост», «текст», «оригинальный», «жизнь», «мочь», «Россия», «место», что тезисно вербализируется в следующем тексте комментария: «Сравнение Сталина с Гитлером - это русофобия», - клеймят они (православные сторонники сегодняшнего культа Сталина. - Прим. aвm.) не согласных с идеей, что Сталин был большим почитателем России, русского народа, русской православной культуры и никогда не уничтожал людей в количествах, соотносимых с военными потерями... Еще осенью 1941 г., когда немцы рвались к Москве, вождь все четко разъяснил. «Они сражаются не за нас, - сказал тогда Сталин главе американской делегации на международном совещании в Москве А. Гарриману. - Они воюют за свою Россию»1.

Дискурс ущемления прав личности в России.

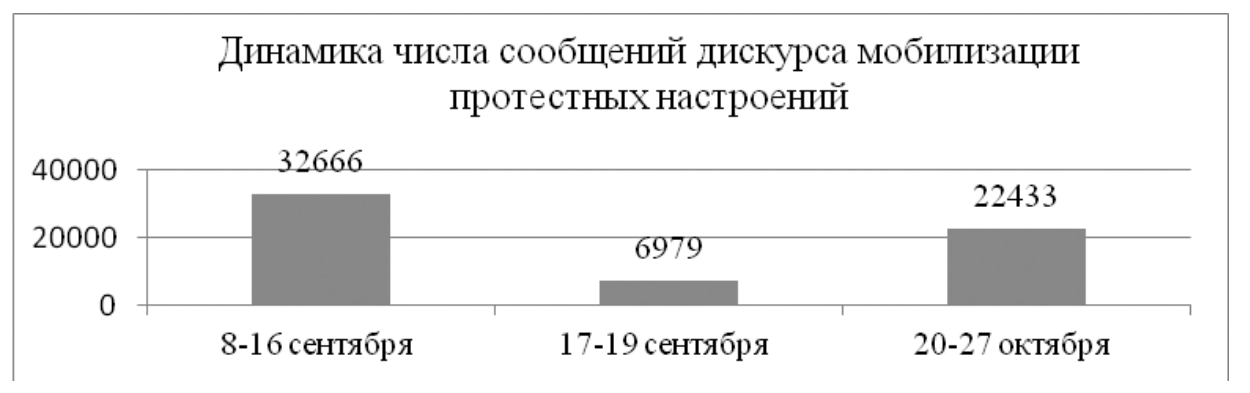

Рисунок 2. Дискурс ущемления прав личности в России

Наибольшая активность по данному информационному потоку зафиксирована в период с 8 по 16 сентября и с 20 по 27 сентября 2021 г. (см. рис. 2). Примечательно, что для всех временных отрезков гендерная характеристика имеет существенные отличия. Так, авторами большинства сообщений являются мужчины, активность которых варьируется от 73,7\% до 71,9\%, при этом женская аудитория составила от $28,1 \%$ до $26,3 \%$ всего контента данного дискурса.

Для дискурса ущемления прав личности в России характерна следующая возрастная тенденция: социальная база всех периодов представлена аудиторией в возрасте 36-45 лет, т.е. экономически активное, профессиональное население. Следующими по численности, но не менее активными оказались авторы в возрасте 26-35 лет. Наибольшую активность представители данных возрастов

\footnotetext{
1 https://vk.com/wall-65370749_11623?reply=11626 (проверено 14.09.2021).
} 
проявили в период с 8 по 16 сентября. Меньше всего в дискуссию были вовлечены представители младше 16 лет.

Номинативный набор наиболее употребляемых слов всех периодов представляют такие маркеры, как «Россия», «человек», «пост», «текст», «оригинальный», что имеет некоторое сходство с дискурсом несвободы слова и СМИ в РФ. Ярким примером является следующее выражение: «У нас отнимают, а вернее, уже отняли право выбирать, право голоса, право иметь свое мнение. То, что сейчас власть сделала с ФБК, с Умным голосованием - это самый настоящий тоталитаризм» 1 .

Дискурс мобилизации протестных настроений.

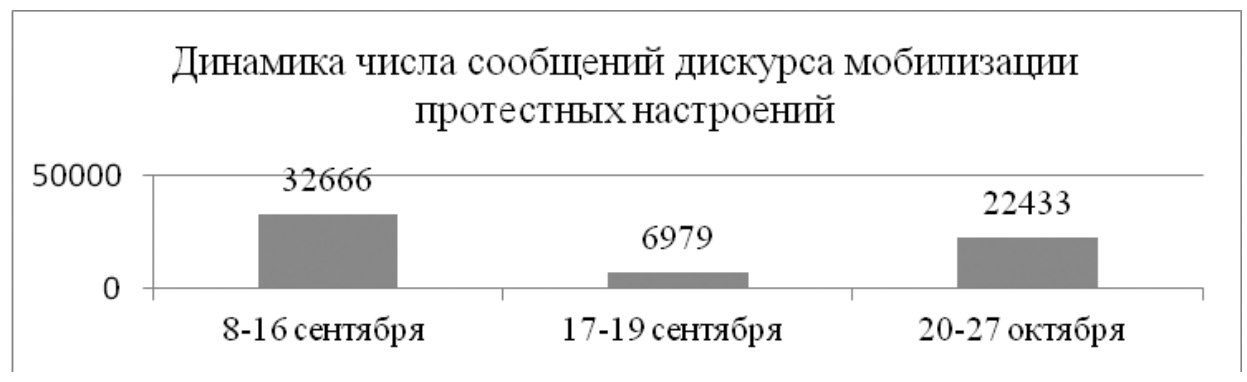

Рисунок 3. Дискурс мобилизации протестных настроений

Наибольшая активность аудитории в отношении мобилизации протестных настроений присуща периоду агитации и подготовки к ЕДГ (8-16 сентября 2021 г.). На втором месте временной промежуток с 20 по 27 октября, а наименьшая активность по данному вопросу отмечена с 17 по 19 сентября (см. рис. 3).

Для всех анализируемых периодов характерна наибольшая активность представителей возрастных когорт 36-45 лет, 26-35 лет, 46-55 лет, наименьшая младше 16 лет, и нигде нет представителей старше 65 лет. Такая же тенденция для всех временных отрезков исследования отмечается и по гендерной активности аудитории. Так, в среднем мужчины составили приблизительно 55\%, а женщины - $45 \%$ общего числа авторов.

Смысловое наполнение дискурса мобилизации протестных настроений отмечено общностью наиболее употребляемых номинаций, таких как «человек», «пост», «текст», «оригинальный», «мочь». Дискурс данного информационного потока присутствует в сообщениях, связанных с ЕДГ: «Мы - не шелупонь! И мы не раз это доказывали им. Видимо, пришло время показать это в очередной раз - на выборах в это воскресенье 19 сентября!» 2

Дискурс осудительного отношения к ограничительным мерам по нераспространению пандемии. Дискурс критики ограничительных мер по нераспространению пандемии является устойчивым и стабильным вне привязки к периоду ЕДГ-2021 (см. рис. 4). Данный информационный поток равно поддерживается мужской и женской аудиторией: $56 \%$ мужчин и $44 \%$ женщин. Необходимо отметить, что данный дискурс артикулируется в большей степени молодой аудиторией: $28 \%$ авторов относятся к возрастной группе 26-35 лет, при этом аудитория в возрасте 56-65 лет составляет лишь 15\%. С одной стороны,

\footnotetext{
1 https://vk.com/wall12804231_5950 (проверено 22.01.2022).

2 https://vk.com/wall-37934275_535827 (проверено 22.01.2022).
} 


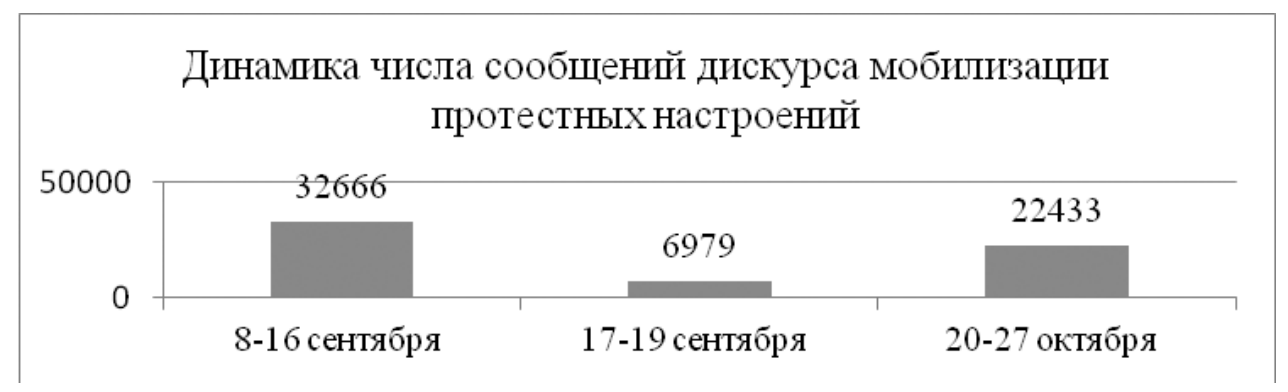

Рисунок 4. Дискурс критики ограничительных мер по нераспространению пандемии

старшее поколение в меньшей степени вовлечено в сетевые коммуникации, однако, учитывая распространение социальных сетей во всех возрастных группах, такой показатель достаточно репрезентативен.

Наиболее ярко данный тип дискурса характеризует пользовательский резонанс по поводу вакцинации и завершения испытания вакцины для детей: «Дорогие женщины, если вы за себя не пожелали биться с преступной властью, то хотя бы ради своих детей поднимайтесь на смертный бой. Ведь кремлевский кагал в прямом смысле готовится калечить и убивать ваших детей» 1 . Многие пользователи связывали сообщения с окончанием выборной кампании: «Не успели закончиться выборы в России, как главный внештатный педиатр Минздрава Александр Баранов предложил ввести обязательную вакцинацию от ковида детей» ${ }^{2}$.

Дискурс осудительного отношения к сторонникам президента.

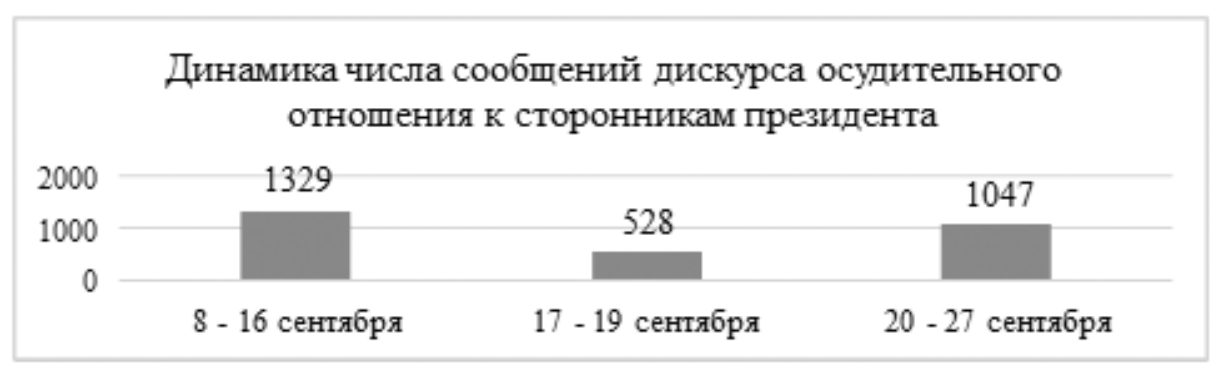

Рисунок 5. Динамика числа сообщений дискурса осудительного отношения к сторонникам президента

Эскалация информационного потока, связанного с критикой сторонников президента, была особенно заметна в период голосования с 17 по 19 сентября 2021 г. (см. рис. 5). Анализ свидетельствует, что социально-медийная критика сторонников президента и действующей власти в целом в большей степени была привязана к политическим событиям. После выборов на первый план выходит дискурс критики личности В. Путина и власти в целом.

Социально-демографические показатели данного дискурса менее сбалансированы - на долю мужчин приходится 78,8\% публикуемых материалов, на

\footnotetext{
1 https://vk.com/wall399748337_9775 (проверено 22.01.2022).

2 https://vk.com/wall157259893_29179 (проверено 22.01.2022).
} 
долю женщин - 21,1\%. Социальную базу информационного потока составляет аудитория 26-45 лет, т.е. экономически активное население. На втором месте - молодежь от 16 до 25 - 20\%. Что касается смыслового наполнения дискурсивных практик, то в данном случае дискурс формируется на фоне дискредитации партии власти и президента, триггером которой становились выявляемые нарушения процедуры подсчета голосов на избирательных участках. Пользователи активно распространяли (репостили) видео с фактами нарушений: «В Петербурге УИК 2127 председатель-запутинец украл сейф-пакет с избирательного участка. Очевидно, что твари потом туда фальшивые бюллетени положат» 1 .

Дискурс осудительного отношения к президенту и действующей власти в целом.

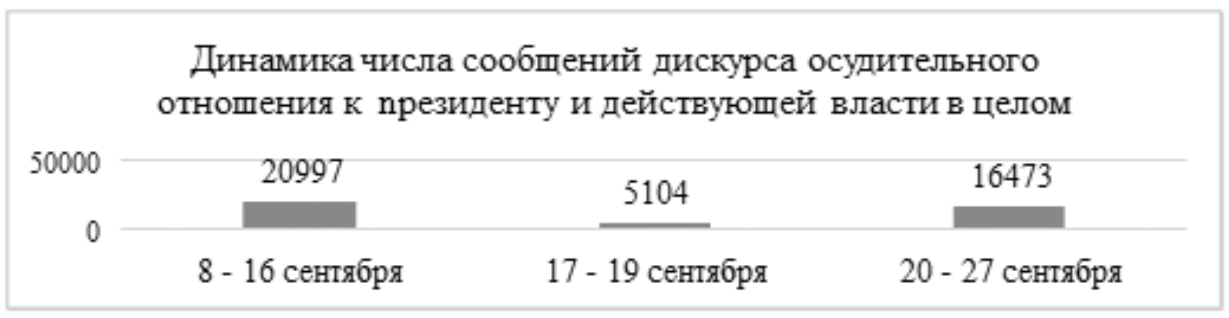

Рисунок 6. Динамика числа сообщений дискурса осудительного отношения к президенту и действующей власти в целом

Социальную базу информационного потока составляют мужчины - в среднем $72,6 \%$, женская аудитория тиражировала лишь $27,4 \%$ контента. В целом доминирование мужской аудитории в потоках политического активизма объясняется большей вовлеченностью мужчин в политику и готовностью выражать протестные настроения.

Социальную базу информационного потока составляет аудитория 26-45 лет, т.е. экономически активное население, - на них в среднем приходится $62 \%$ авторов сообщений. Молодежь 16-25 лет незначительно вовлечена в информационный поток - данная аудитория транслирует лишь $10 \%$ контента.

Наиболее ярко дискурс осудительного отношения к президенту отражается в постах, отражающих критику так называемого обнуления и фальсификации выборов: «Вы прекрасно понимаете, что и без обнуления этих сроков Путин в любом случае может оставаться в президентах до последнего, а потом мафия через такие же фальшивые выборы посадит на это место его преемника» 2 .

Резюмируя анализ динамики маркеров интенсивности и маркеров содержания в радикальном дискурсе социальных медиа, отметим, что исследование зафиксировало нарастание эскалации материалов с резко оппозиционным контентом в отношении действующей власти и ее сторонников непосредственно перед началом ЕДГ-2021 и устойчивость критики ограничительных коронавирусных мер до и после выборов. Наиболее активной когортой, выражающей недовольство действиями власти в указанный период, чаще всего выступали мужчины экономически активного возраста $26-35$ и $36-45$ лет.

\footnotetext{
1 https://ok.ru/profile/360117025464/statuses/154100206560184 (проверено 06.11.2021).

2 https://vk.com/wall301763427_17301?reply=17302 (проверено 06.11.2021).
} 
Таким образом, лидеры радикальной оппозиции создают дезинтеграционную повестку в цифровом пространстве, общественная поддержка которой связана с весомой долей социально депривированных россиян. Эксплуатируя контексты нерешенных социальных вопросов, усиливающихся на фоне экономических последствий пандемии, радикальные акторы способствуют социальной деконсолидации, обострению общественных противоречий, углублению фрустрации части россиян в восприятии социального расслоения. Радикальная риторика довольно часто мимикрирует под псевдорациональные доводы радикального содержания по отношению к действующему политическому режиму и социальному устройству, используются технологии манипуляции и стереотипизации массового сознания, подрывающие доверие российских граждан к действующей власти.

\section{Список литературы}

Бродовская Е.В., Домбровская А.Ю., Карзубов Д.Н., Чередник А.В. 2018. Состояние и динамика русскоязычных потоков о межнациональных и межрелигиозных отношениях в Крыму и Севастополе: киберметрия и дискурс-анализ сообщений социальных медиа Рунета. - Гуманитарные науки. Вестник Финансового университета. Т. 8. № 4(34). С. 23-35.

Домбровская А.Ю. 2021а. Правозащитные информационные потоки в социальных медиа в структуре цифровой репрезентации гражданской активности россиян в 2020 году: результаты социально-медийного анализа. - Гуманитарные науки. Вестник Финансового университета. № 11(2). С. 102-110.

Домбровская А.Ю. 2021б. Цифровые потоки российской радикальной оппозиции: дискурсы, динамика, социальная база (2021 год). - Известия Тульского государственного университета. Гуманитарные науки. № 4. С. 79-93.

Пырма Р.В. 2020. Структура сетевых сообществ социальных медиа в информационном потоке внешнего давления на Крым. - Гуманитарные науки. Вестник Финансового университета. № 10(4). С. 65-72.

Сморгунов Л.В. 2019. Партисипаторная управляемость в условиях цифровизации: сетевой эффект и институты. - Каспийский регион: политика, экономика, культура. № 4(61). С. 43-49.

Чернявская В.Е. 2014. «Когнитивное в формате»: о формировании медиальной парадигмы в лингвистике. Стилистика сегодня и завтра: материалы конференции. Ч. І. М.: факультет журналистики МГУ им. М.В. Ломоносова. C. 242-248.

Чурашова Е.А. 2013. Дискурсивные стратегии политической коммуникации в кризисной ситуации: автореф. дис. ... к.полит.н. М. 21 с.

Knoke D. 1990. Political Networks: The Structural Perspective. Cambridge: Cambridge University Press. 290 p. 
BELUGINA Nadezhda Borisovna, Assistant at the Department of Mass Communications and Media Business, Financial University under the Government of the Russian Federation (49 Leningradsky Ave, GSP-3, Moscow, Russia, 125993; belugina.nb@gmail.com)

RYAZANOVA Liliya Vyacheslavovna, Manager of the Institute of Financial Literacy, Financial University under the Government of the Russian Federation (49 Leningradsky Ave, GSP-3, Moscow, Russia, 125993; liliya_ryazanova@ mail.ru)

\section{INFORMATION STREAMS OF RADICALS IN RUNET ON THE EVE AND AFTER EDG-2021: CONTEXTS, TARGET GROUPS AND THE SCALE OF PUBLIC SUPPORT}

Abstract. The article presents the results of a comparative analysis of quantitative, structural and content parameters of social media users' messages related to radical information flows on the eve and after the EDG-2021. The research model is a combination of methods of cybermetric and discourse analysis of online content generated by users of the Russian segment of social media and related to the topic of elections in 2021. The study revealed quantitative and qualitative changes in the radical information agenda, the thematic distribution of the discourse of information flows.

Keywords: Internet space, social media, political communication, political discourse, cybermetric analysis, discourse analysis, protest activity 